\title{
A systematic review on the quality of life benefits after aortic valve replacement in the elderly
}

\author{
Leonard Shan, MBBS, BMedSc, ${ }^{\text {a }}$ Akshat Saxena, MBBS, BMedSc, ${ }^{\mathrm{b}}$ Ross McMahon, MBBS, ${ }^{\mathrm{b}}$ \\ Andrew Wilson, MBBS, PhD ${ }^{c}$ and Andrew Newcomb, $\mathrm{MBBS}^{\mathrm{a}, \mathrm{d}}$
}

\begin{abstract}
Background: Surgical aortic valve replacement is being increasingly performed in elderly patients with good perioperative outcomes and long-term survival. Evidence is limited on health-related quality of life after aortic valve replacement, which is an important measure of operative success in the elderly.
\end{abstract}

\begin{abstract}
Methods: A systematic review of clinical studies after January 2000 was performed to identify health-related quality of life in the elderly after aortic valve replacement. Strict inclusion and exclusion criteria were applied. Quality appraisal of each study also was performed using predefined criteria. Health-related quality of life results were synthesized through a narrative review with full tabulation of the results of all included studies.
\end{abstract}

\begin{abstract}
Results: Health-related quality of life improvements were shown across most or all domains in different health-related quality of life instruments. Elderly patients experienced marked symptomatic improvement. Health-related quality of life was equivalent or superior to both an age-matched population and younger patients undergoing identical procedures. There were excellent functional gains after surgery, but elderly patients remain susceptible to geriatric issues and mood problems. Concomitant coronary artery bypass did not affect healthrelated quality of life. There was a diverse range of study designs, methods, and follow-up times that limited direct comparison between studies.
\end{abstract}

Conclusions: Aortic valve replacement results in significant health-related quality of life benefits across a broad range of health domains in elderly patients. Age alone should not be a precluding factor for surgery. Data are heterogeneous and mostly retrospective. We recommend future studies based on consistent guidelines provided in this systematic review. (J Thorac Cardiovasc Surg 2013;145:1173-89)

According to the United Nations Population Division, the world's population is aging at a rapid and unprecedented rate that is expected to persist at least until $2050 .{ }^{1}$ Within developed countries, the proportion of people aged more than 60 years is projected to double from $11 \%$ to $22 \%$ ( 2 billion people) by $2050 .{ }^{1}$ By 2025 , people aged more than 65 years will account for $21.3 \%$ of the population. ${ }^{1}$ The number of very elderly people aged more than 80 years is projected to increase by a factor of 26 compared with a factor of 10 and 3.7 for those aged more than 60 years and the total world population, respectively. ${ }^{1}$ The increasingly aging population will create an increased demand for treatment of degenerative aortic valve diseases, the most common site of valvular pathology in the elderly. ${ }^{2,3}$ A quarter of the

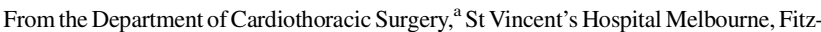
roy, Victoria, Australia; Department of Medicine, ${ }^{\mathrm{b}}$ South Eastern Sydney and Illawarra Health Network, Wollongong, Australia; Department of Cardiology, ${ }^{\mathrm{c}}$ St Vincent's Hospital Melbourne, Fitzroy, Victoria, Australia; and University of Melbourne Department of Surgery, ${ }^{\mathrm{d}}$ St Vincent's Hospital Melbourne, Fitzroy, Victoria, Australia. Disclosures: Authors have nothing to disclose with regard to commercial support.

Received for publication Oct 6, 2012; revisions received Dec 18, 2012; accepted for publication Jan 11, 2013; available ahead of print Feb 18, 2013.

Address for reprints: Akshat Saxena, MBBS, BMedSc, Cardiology Unit, South Eastern Sydney and Illawarra Health Network, Wollongong, New South Wales, Australia (E-mail: akshat16187@gmail.com). $0022-5223 / \$ 36.00$

Crown Copyright (C) 2013 Published by Elsevier Inc. on behalf of The American Association for Thoracic Surgery

http://dx.doi.org/10.1016/j.jtcvs.2013.01.004
}

population aged more than 65 years will have aortic sclerosis, ${ }^{2,4}$ and $9 \%$ of these patients will progress to aortic stenosis over 5 years. ${ }^{5}$ A large population study estimates a prevalence of $2.8 \%$ for aortic stenosis and $2.0 \%$ for aortic regurgitation in those aged more than 75 years. ${ }^{6}$

Aortic stenosis has a dismal natural course and remains one of the most common causes of morbidity and mortality in the elderly. ${ }^{7}$ Without surgical intervention, 2-year mortality rates reach $90 \%$ in symptomatic patients, which is a 12-fold increased mortality risk compared with surgically treated patients. ${ }^{8-10}$ Attempts at conservative treatment also are largely unsuccessful. ${ }^{11}$ Rapidly improving surgical standards and postoperative care have resulted in improved survival while maintaining low operative mortality after aortic valve replacement (AVR) in the elderly., ${ }^{20,12-15}$

Despite good operative morbidity and mortality, these parameters alone do not give enough information on a patient's physical, functional, emotional, and mental well-being. ${ }^{16}$ Postoperative health-related quality of life (HRQOL) is a primary goal of surgery in the elderly and an important aspect for many patients in their decision-making. ${ }^{17}$ The challenge of surgery in this population is to provide a good HRQOL in the mid- to long-term. Evidence is accumulating on the positive HRQOL outcomes after AVR, ${ }^{8,12,14,15,18-32}$ and it remains the only effective treatment option for aortic valve disease. ${ }^{29}$ AVR is also highly cost-effective in the elderly population, ${ }^{33}$ yet it is still withheld from elderly 


Abbreviations and Acronyms
$\begin{aligned} \text { AVR } & =\text { aortic valve replacement } \\ \text { HRQOL } & =\text { health-related quality of life } \\ \text { NHP } & =\text { Nottingham Health Profile } \\ \text { NYHA } & =\text { New York Heart Association } \\ \text { QOL } & =\text { quality of life } \\ \text { SF-36 } & =\text { Medical Outcomes Survey } \\ & \text { Short-Form } 36 \\ \text { WHO } & =\text { World Health Organization }\end{aligned}$

patients. Up to one third of patients do not receive necessary operations ${ }^{7,13,34}$ despite current guidelines recommending that all elderly patients with symptomatic aortic stenosis should be considered for AVR. ${ }^{35}$ Considering that life expectancy is 17.1 years at age 65 years and 8.2 years at age 80 years, ${ }^{1}$ there is a significant opportunity for elderly patients to improve their HRQOL and survival if they are offered surgery.

\section{OBJECTIVES}

We conducted a systematic review of publications from the start of this millennium to investigate the effect of AVR on HRQOL in elderly patients aged more than 70 years. This systematic review aims to (1) summarize the literature and clarify strengths and weaknesses of current evidence on HRQOL after AVR in the elderly, (2) demonstrate whether there is a HRQOL benefit in elderly patients after AVR and whether it is enough to justify surgery, and (3) outline guidelines for future research.

\section{MATERIALS AND METHODS}

The structure of this systematic review followed previously recommended guidelines ${ }^{36}$ and was written in accordance with the PRISMA checklist for systematic reviews. ${ }^{37}$

\section{Definition and Measurement of Health-Related Quality of Life}

The World Health Organization (WHO) has defined health as being "not only the absence of disease and infirmity but also the presence of physical, mental, and social well-being." ${ }^{38}$ HRQOL encapsulates an individual's physical, emotional, and psychologic health, as well as social and functional status. ${ }^{39}$ Because HRQOL is not a tangible entity, a standardized method of measurement is required that is reliable, valid, responsive, and sensitive, and that covers all health domains. ${ }^{39}$

In valvular heart disease, disease-specific quality of life (QOL) measures aim to accurately reflect a patient's experience of a specific illness or its treatment. A common tool is New York Heart Association (NYHA) classification, ${ }^{40}$ but the Minnesota Living with Heart Failure Questionnaire $^{41}$ and Kansas City Cardiomyopathy Questionnaire ${ }^{42}$ also have been used. Generic HRQOL instruments are required to facilitate holistic and quantitative comparisons between different groups of patients. According to the WHO's QOL group, any generic HRQOL instrument should include physical, psychologic, social, functional, and well-being domains. ${ }^{43}$ Wellrecognized HRQOL instruments in cardiac surgery are the Medical
Outcomes Survey Short-Form 36 (SF-36), ${ }^{44-47}$ Nottingham Health Profile (NHP), ${ }^{48,49}$ EuroQOL (EQ-5D), ${ }^{50}$ and Medical Outcomes Survey Short-Form 12. ${ }^{51,52}$ More detailed descriptions of each scoring system and HRQOL instrument are shown in Table 1.

\section{Eligibility Criteria}

Study characteristics were as follows: (1) elderly patients defined as aged more than 70 years; (2) greater than $50 \%$ operations performed were AVR or AVR and concomitant CABG; (3) comparisons made with preoperative status, younger patients undergoing similar procedures, or an age-matched general population; (4) HRQOL methods of assessment and results reported; and (5) retrospective and prospective investigative studies. Report characteristics were (1) publication date during or after the year 2000, (2) fully published status, and (3) English language.

\section{Literature Search and Information Sources}

A literature search was conducted using a MeSH keyword search via PubMed. Strict inclusion criteria for study characteristics were applied as described. On August 29, 2012, a search was conducted as described in Figure 1. A subsequent additional manual search was conducted to identify studies not covered by the initial MeSH keyword search. These manual search articles were sourced from the EMBASE, DISCOVERY, and MEDLINE databases, as well as bibliographies of each included study. Authors were e-mailed when original PDF documents could not be sourced.

\section{Study Selection}

Two reviewers screened titles and abstracts after both MeSH keyword and manual searches. Studies were excluded if they did not meet eligibility criteria. If the information required to determine eligibility was not in the abstract, a second pass was run after data extraction. Reviewers were not blinded.

\section{Data Items and Collection Process}

Data extraction was then performed in 2 phases by 2 reviewers using standardized pilot forms. The first phase involved assessment of study quality (Table 2), and the second phase collected results of the studies reviewed (Table 3). All data items were predetermined and specified in these tables.

\section{Assessment of Risk of Bias}

Risk of bias in individual studies was mainly assessed by evaluating the (1) study design, (2) number of patients, (3) use of a generic HRQOL instrument, and (4) questionnaire response rates.

\section{RESULTS}

After careful systematic selection, 19 studies were included in this systematic review. $8,12,14,15,18-24,26,28-32,53,54$ Full details and results of reviewed articles are provided in Tables 2 and 3.

\section{Early Mortality}

The studies included in this review showed an acceptable early mortality after AVR (Table 4). Early mortality was generally low in contemporary studies and in isolated AVR procedures.

\section{Cardiac-Specific Quality of Life Measures}

Elderly patients appear to have marked symptomatic improvements after AVR. Within the first 18 months after operation, only $0 \%$ to $20 \%$ of patients are in NYHA III/IV. ${ }^{12,21,29}$ The improvement in NHYA class persists 
TABLE 1. Description of scoring systems and health-related quality of life instruments

\begin{tabular}{|c|c|c|}
\hline System & & Components \\
\hline \multirow[t]{3}{*}{ MLHFQ $^{41}$} & \multicolumn{2}{|c|}{ Effects of heart failure on QOL asked through 21 questions covering physical and emotional dimensions } \\
\hline & Physical & $\begin{array}{l}\text { Lower-limb edema, limiting ambulation, difficulty leaving the house, limiting } \\
\text { occupation, limiting recreational activities, limiting sexual activity, shortness of } \\
\text { breath, fatigue, } \\
\text { hospitalization, treatment side effects, }\end{array}$ \\
\hline & Emotional & $\begin{array}{l}\text { insomnia, difficulty relating/interacting with people, eat less foods previously enjoyed, } \\
\text { financial costs, feel like burden to family or friends, feel like losing control of life, } \\
\text { worry, difficulty concentrating or remembering, feeling depressed }\end{array}$ \\
\hline \multirow[t]{4}{*}{$\mathrm{NYHA}^{40}$} & Class I & No limitations on physical activity, no symptoms with ordinary activity \\
\hline & Class II & Slight limitation on physical activity, mild symptoms on ordinary activity \\
\hline & Class III & Marked limitation on physical activity, symptomatic at less than ordinary activity levels \\
\hline & Class IV & Unable to perform any activity, discomfort with any activity, symptomatic at rest \\
\hline $\mathrm{KCCQ}^{42}$ & \multicolumn{2}{|c|}{$\begin{array}{l}\text { There are } 23 \text { items measuring self-reported health status in patients with heart failure. Scales measured are physical limitation, symptom } \\
\text { stability, symptom frequency, symptom burden, total symptoms, self-efficacy, QOL, social limitation, overall summary, and clinical } \\
\text { summary. }\end{array}$} \\
\hline SF-36 $6^{44-47}$ & \multicolumn{2}{|c|}{36 (or 12 ) items measuring 8 conceptual domains or dimensions of health: } \\
\hline \multirow[t]{10}{*}{ SF- $12^{51,52}$} & General health & Measurement of perceived overall health, including past and present health \\
\hline & Physical functioning & Indicates level of limitations in lifting, bending, kneeling, or walking moderate distance \\
\hline & Bodily pain & $\begin{array}{l}\text { Represents the intensity, frequency, and duration of bodily pain and limitations in } \\
\text { normal activities due to pain }\end{array}$ \\
\hline & Mental health & Measures the emotional, cognitive, and intellectual status of the patient \\
\hline & Role physical & Measures the degree in performing of usual activities for age and social status \\
\hline & Role emotional & Measures personal feeling of job performance at work or other activities \\
\hline & Vitality & Measures feeling of energy, fatigue, and tiredness \\
\hline & Social functioning & Indicates ability to develop and maintain mature social relationships. \\
\hline & \multirow{2}{*}{\multicolumn{2}{|c|}{$\begin{array}{l}\text { The SF-36 scores can be related to activities of daily living. For example, } 80 \% \text { of responders who judged their general health as being } \\
\text { good, very good, or excellent had a score of } 61 \text { in the general health scale of SF- } 36 .^{61} \\
\text { Note: Both SF-36 and SF-12 surveys can provide } 2 \text { summary measures-physical component score and mental component score. }\end{array}$}} \\
\hline & & \\
\hline \multirow[t]{7}{*}{$\mathrm{NHP}^{48,49}$} & \multicolumn{2}{|c|}{38 yes/no statements on health problems covering 6 dimensions of subjective health: } \\
\hline & Physical mobility & $\begin{array}{l}\text { Only walk indoors, difficult to bend, unable to walk, trouble with stairs, difficult to reach } \\
\text { for things, difficult to dress, hard to stand for long times, needs help walking outside }\end{array}$ \\
\hline & Pain & $\begin{array}{l}\text { Pain at night, unbearable pain, pain on movement, pain on walking, pain on standing, } \\
\text { constant pain, pain with stairs, pain on sitting }\end{array}$ \\
\hline & Sleep & $\begin{array}{l}\text { Require sleeping tablets, early morning wakening, awake most of the night, takes a long } \\
\text { time to get to sleep, insomnia }\end{array}$ \\
\hline & Energy level & Tiredness, everything is an effort, easily run out of energy \\
\hline & Emotional reactions & $\begin{array}{l}\text { Feeling down, anhedonia, feeling on edge, day seems to drag, easily lose temper, feel } \\
\text { like losing control, ruminating at night, feel like life is not worth living, wake up } \\
\text { feeling depressed }\end{array}$ \\
\hline & Social isolation & $\begin{array}{l}\text { Feeling lonely, difficult to make contact with people, feels close to no one, feel like a } \\
\text { burden to people, difficulty interacting with people }\end{array}$ \\
\hline \multirow[t]{6}{*}{ EuroQOL $^{50}$} & \multicolumn{2}{|l|}{5 domains of EQ-5D index: } \\
\hline & Mobility & Ability to walk \\
\hline & Self-care & Ability to dress \\
\hline & Usual activities & Activities of daily living \\
\hline & Pain/discomfort & Level of pain \\
\hline & Anxiety/depression & Level of anxiety of depression \\
\hline
\end{tabular}

QOL, Quality of life; $M L H F Q$, Minnesota Living with Heart Failure Questionnaire; NYHA, New York Heart Association; KCCQ, Kansas City Cardiomyopathy Questionnaire; $S F-36$, Medical Outcomes Survey Short-Form 36; SF-12, Medical Outcomes Survey Short-Form 12; NHP, Nottingham Health Profile.

long-term, with $35 \%$ to $81.7 \%$ less patients in NYHA III/ IV compared with preoperatively. $8,18,19,22,23,26,29$ Some studies demonstrate $0 \%$ of patients in NYHA III/IV at follow-up. ${ }^{15,18}$ Salazar and colleagues ${ }^{29}$ reported $62.4 \%$,
$0 \%$, and $3.8 \%$ of patients with a preoperative, 1-year, and 5-year NYHA III/IV, respectively. The eventual increase in NYHA scores at 5 years is small and consistent with a natural age-related decline. 


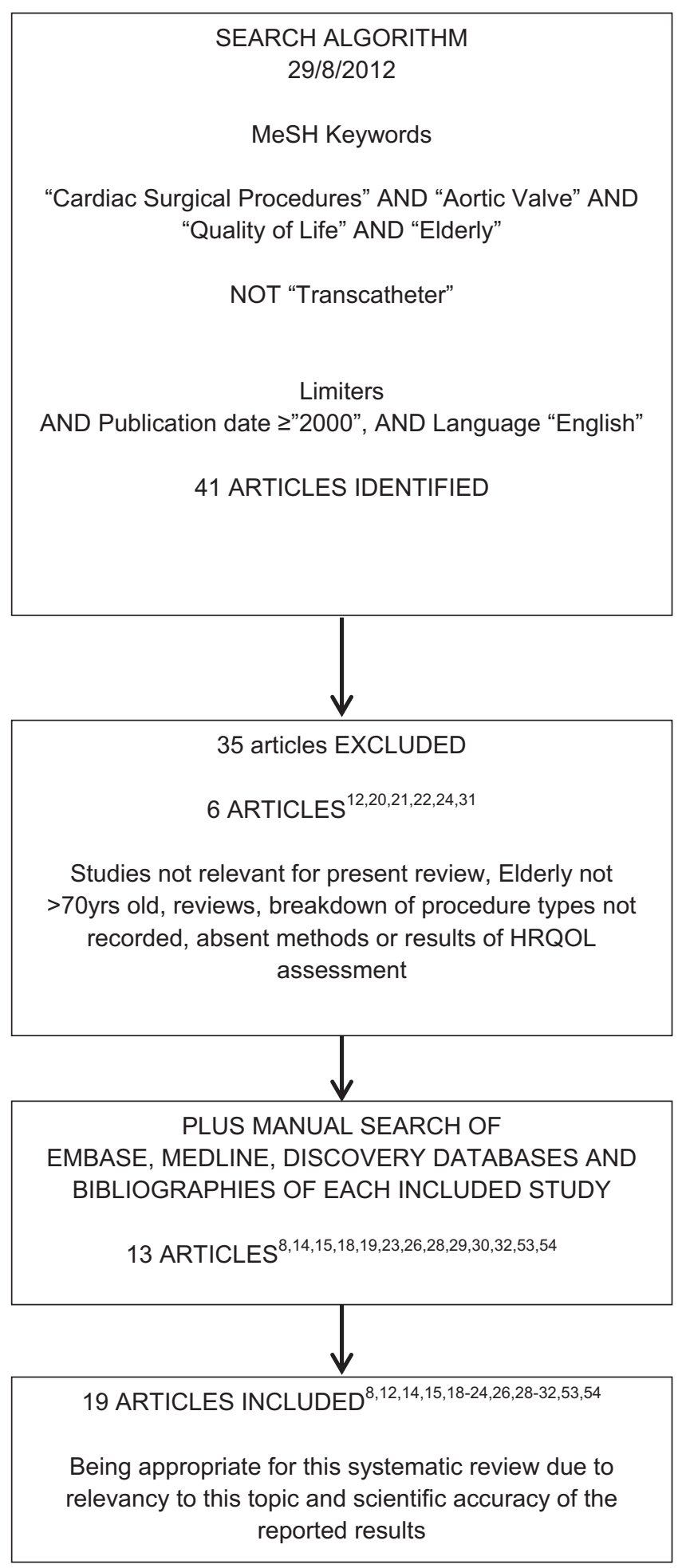

FIGURE 1. Search algorithm. HRQOL, Health-related quality of life.

\section{Generic Health-Related Quality of Life Instruments}

Only 2 authors investigated preoperative compared with postoperative HRQOL. At 1, 6, and 12 months, elderly patients had had highly statistical and clinically significant improvements in Medical Outcomes Survey Short-Form 12 and EQ-5D scores compared with their preoperative status. ${ }^{24,54}$

Comparison with an age-matched general population shows that elderly patients have equivalent or superior HRQOL scores after surgery. ${ }^{12,14,20,23,30,31,53}$ There were 4 studies published by Vicchio and colleagues ${ }^{14,31,53}$ included in this review, and all demonstrated significantly higher SF-36 scores than the age-matched general population in most or all of the 8 domains. Sundt and colleagues ${ }^{12}$ and Lam and Hendry ${ }^{23}$ corroborate these results with their finding that octogenarians have better bodily pain, social function, general health, and mental health scores than the general elderly population, including those 5 years younger. Studies using other HRQOL instruments also appear to demonstrate significantly better scores. Ennker and colleagues ${ }^{20}$ studied the use of stentless bioprosthetic valves in octogenarians and found NHP scores better in all domains except for energy. A significant gender difference was found. Women had a slower recovery on Minnesota Living with Heart Failure Questionnaire scores and may benefit from discharge to a convalescence resource. ${ }^{30}$

Elderly patients can achieve a similar or better HRQOL compared with younger patients undergoing the same procedure. Lam and Hendry ${ }^{23}$ found that compared with patients aged less than 80 years, patients aged more than 80 years had better postoperative bodily pain, vitality, social function, and mental health scores and equivalent scores in all other domains on the SF- 36 .

\section{Self-Constructed Measures of Quality of Life}

Elderly patients derived significant functional gains from AVR. Up to $90 \%$ were able to resume normal activities for their age, ${ }^{21,29}$ and most could undertake moderate to heavy levels of activity. ${ }^{18,19,22}$ This is reflected by a large proportion of patients feeling as good as or better than they did preoperatively, ${ }^{21,22,26}$ such that many patients reported they were independent of their activities of daily living. ${ }^{18,21,26,28}$ Approximately $100 \%$ of patients were satisfied with their decision to undergo surgery and would be willing to undergo another operation. $^{18,19,21,22,26}$

Maillet and colleagues ${ }^{8}$ studied frailty and HRQOL in octogenarians and had less positive results. A lower proportion of patients reported positive general self-rated health or QOL scores. Only $66.1 \%$ of patients considered that their health had improved since the operation, and $60.7 \%$ of patients would have another AVR. Geriatric parameters, especially gait problems and falls, reflected a frail cohort of patients after operation. Self-rated mood also was less optimistic, with half of patients admitting to having "sad ideas" and $33.9 \%$ having anhedonia. 


\section{Concomitant Coronary Artery Bypass Grafting}

Despite improvement on functional and social domains of HRQOL being less for AVR compared with CABG, HRQOL still strongly increases within each procedure group. ${ }^{24}$ Furthermore, Vicchio and colleagues ${ }^{24}$ report no differences in long-term HRQOL according to the presence of concomitant $\mathrm{CABG}$.

\section{DISCUSSION}

\section{Strength of Evidence and Bias}

The strength of evidence was analyzed systematically in this review. Detailed results are shown in Table 2.

Heterogeneous data and lack of quantitative results $^{12,14,15,20,23}$ prevented direct comparison of results or meta-analyses. There was also a variety of patient characteristics. In particular, the proportion of men ranged from $21 \%$ to $65.5 \%$. Urgent operations comprised $45.5 \%$ of procedures in the study by Nikolaidis and colleagues ${ }^{26}$ and 10 studies did not record this information. $8,14,20,21,23,29,30,32,53$ Only 2 studies were retrospective. ${ }^{23,54}$ The retrospective design has inherent bias and contributes to a lack of data on whether these patients improved from their preoperative state and by what magnitude. Small patient numbers limit the generalizability of these results.

The SF-36 was the most commonly used HRQOL instrument. ${ }^{12,14,23,30-32,53}$ A validated HRQOL instrument was not used in 9 studies, which may have resulted in inadequate coverage of the WHO's HRQOL definition. $8,15,18,19,21,22,26,28,29$ The subjective nature of a patient's perception of his or her HRQOL requires validated HRQOL instruments, such as SF-36 and NHP, to accurately assess a patient's HRQOL across all domains. Despite this, NYHA scores were used in isolation even though they are not originally designed as HRQOL instruments. $8,12,15,18,19,22,23,26,29,30$

According to previous guidelines, a response rate of more than $85 \%$ (loss to follow-up $<15 \%$ ) is considered ideal for treatment-received analyses. ${ }^{36}$ Only 3 articles did not achieve this mark. $^{23,26,30}$ There were 4 studies that did not report their response rates or were not available because of the inability to source the original documents. ${ }^{8,18,21,24}$ Authors were contacted, but there was no reply. A relatively good followup consistency was demonstrated in the population studied. This may be attributed to questionnaires administered by telephone, ${ }^{12,19,20,28,31,53}$ which are considered to be more reliable and to have higher response rates than selfadministered postal questionnaires. ${ }^{55}$ The precision of HRQOL results is dependent on the confidence interval, range, or standard error of instrument scores, but only 4 articles recorded this information. ${ }^{19,20,30,54}$

Whereas there were abundant data with a late follow-up time point of greater than 2 years, ${ }^{8,14,15,18-20,22,23,26,28-32,53}$ evidence on early HRQOL outcomes after AVR remains scarce. ${ }^{12,21,54}$ Furthermore, 4 studies were published 5 or more years after the completion of the study period. ${ }^{8,15,23,28}$ Rapid advances in surgical technique and postoperative care mean these results may be less reflective of potential HRQOL benefits with modern operative care.

More well-designed prospective studies are required to make a more reliable assessment on the HRQOL benefits for elderly patients undergoing AVR. We recognize the obstacles to performing large randomized controlled trials because it is unethical to deny patients surgery when operative morbidity and mortality are excellent. Subsequently, the strength of evidence reviewed in this article is limited. Yet there is a burgeoning elderly population, and AVR is increasingly being performed and required in this age group. This systematic review summarizes the best available evidence on HRQOL after AVR in the elderly.

\section{Summary of Evidence and Interpretation}

The main findings of this systematic review are that elderly patients have (1) noticeable improvements in cardiac symptoms after AVR, ${ }^{8,12,15,18,19,21-23,26,29,30,54}$ (2) equal or better HRQOL compared with an age-matched general population, ${ }^{12,14,20,23,30,31,53}$ (3) equivalent or superior HRQOL compared with younger patients who underwent AVR, ${ }^{23}$ and (4) significant functional gains after surgery. ${ }^{18,19,21,22,26,28-30}$

The long-term symptomatic and functional gains after AVR in both septuagenarians and octogenarians ${ }^{8,12,15,18,19,21-}$ $23,26,28,29$ are important in elderly patients and lead to a highly positive experience. This is reflected in most or all patients being satisfied with their decision to undergo surgery or willing to have another operation. ${ }^{18,19,21,22,26}$ Elderly patients maintain their HRQOL benefits after surgery that allow them to have superior HRQOL than their age-matched counterparts in most studies. ${ }^{12,14,20,23,31,53}$ Age seems to be less important in consideration for surgery, especially when the longer-term HRQOL can be superior to the level of younger patients. ${ }^{23}$

The aging population and increasing life expectancy of patients will lead to continuing increases in degenerative aortic valve disease, necessitating consideration for AVR. There is currently no effective medical treatment for aortic valve lesions. Although there are specific risks of operating in elderly patients, this must be considered in relation to benefits for HRQOL. Despite a need for increasing operations in the elderly, referring physicians may have a perception of poor outcomes after surgery. ${ }^{7,34}$ This results in an increased likelihood of elderly patients being inadequately managed with conservative treatment. Patients are likely to have to ongoing symptoms until a time is demanded for urgent surgery, which is a risk factor for increased mortality. ${ }^{22}$

Despite increases in the age of patients undergoing surgery, mortality after AVR is progressively decreasing. ${ }^{56}$ 
Ð TABLE 2. Quality appraisal

\begin{tabular}{|c|c|c|c|c|c|c|c|c|c|}
\hline \multirow[b]{2}{*}{ Author year (study period) } & \multirow[b]{2}{*}{ Patients } & \multirow[b]{2}{*}{ Study design } & \multicolumn{4}{|c|}{ Methodological quality } & \multicolumn{2}{|c|}{ Precision } & \multirow{2}{*}{$\begin{array}{l}\text { Overal } \\
\text { vstudy } \\
\text { quality }\end{array}$} \\
\hline & & & $\begin{array}{c}\text { Validated HRQOL } \\
\text { instrument }\end{array}$ & $\begin{array}{c}\text { Cardiac-specific } \\
\text { measures }\end{array}$ & Patient demographics & $\begin{array}{l}\text { Method of follow-up and } \\
\text { HRQOL assessment }\end{array}$ & $\begin{array}{l}\text { Follow-up } \\
\text { consistency }\end{array}$ & $\begin{array}{c}\text { Range/C/SE/SD } \\
\text { of results }\end{array}$ & \\
\hline $\begin{array}{l}\text { Sundt and colleagues }{ }^{12} 2000 \\
(1993-1998)\end{array}$ & $\mathrm{n}=133(>80)$ & $\mathrm{R}$ & Yes; $\mathrm{SF}-36$ & Yes; NYHA & $\begin{array}{l}\text { Male 46.6\%, Urgent 10.5\%, } \\
\text { Location: United States } \\
\text { Diabetes 17.3\%, HTN 67.7\%, } \\
\text { Chol NR\%, } \\
\text { COPD 12\%, CRF 5.3\% PVD } \\
12.8 \% \text { CVA } 11.3 \%\end{array}$ & $\begin{array}{l}\text { Baseline NR } \\
\text { By mail or telephone } \\
\text { Repeat attempts NR }\end{array}$ & $\begin{array}{l}48.9 \% \mathrm{PR} \\
98 \% \mathrm{RR}\end{array}$ & $\begin{array}{l}\text { Follow-up: wide } \\
\text { QOL: NR }\end{array}$ & Excellent \\
\hline $\begin{array}{l}\text { Chiappini and colleagues }{ }^{19} \\
2004(1982-2003)\end{array}$ & $\mathrm{n}=115(>80)$ & $\mathrm{R}$ & No; own questions & Yes; NYHA & $\begin{array}{l}\text { Male 40.9\%, Urgent 14.7\%, } \\
\text { Location: Italy } \\
\text { Diabetes 13.8\%, HTN 44.9\%, } \\
\text { Chol 22.2\% } \\
\text { CoPD 19.8\%, CRF NR\%, } \\
\text { PVD NR\%, CVA 5.2\% }\end{array}$ & $\begin{array}{l}\text { Baseline N/A } \\
\text { By telephone interview } \\
\text { Repeat attempts NR }\end{array}$ & $\begin{array}{l}73.0 \% \text { PR } \\
100 \% \text { RR }\end{array}$ & $\begin{array}{l}\text { Follow-up: wide } \\
\text { QOL: moderate }\end{array}$ & Good \\
\hline $\begin{array}{l}\text { Lam and Hendry } 232004 \\
\quad(1995-1999)\end{array}$ & $\mathrm{n}=58(>80)$ & $\mathrm{P}$ & Yes; SF-36 & Yes; NYHA & $\begin{array}{l}\text { Male 62\%, Urgent NR\%, } \\
\text { Location: Canada } \\
\text { Diabetes 12\%, HTN 35\%, } \\
\text { Chol 5\% } \\
\text { COPD 5\%, CRF 9\%, PVD } \\
16 \% \text {, CVA NR\% }\end{array}$ & $\begin{array}{l}\text { Baseline performed } \\
\text { By mail and telephone } \\
\text { Repeat attempts NR }\end{array}$ & $\begin{array}{l}100 \% \mathrm{PR} \\
35 \% \mathrm{RR}\end{array}$ & $\begin{array}{l}\text { Follow-up: wide } \\
\text { QLL: NR }\end{array}$ & Poor \\
\hline $\begin{array}{l}\text { Salazara and colleagues }{ }^{29} 2004 \\
(1991-2002)\end{array}$ & $\mathrm{n}=117(>70)$ & $\mathrm{R}$ & No; own questions (NR) & Yes; NYHA & $\begin{array}{l}\text { Male } 61.5 \% \text {, Urgent NR\%, } \\
\text { Location: Mexico } \\
\text { Diabetes 14.5\%, HTN 43.6\%, } \\
\text { Chol NR\%, } \\
\text { COPD 32.5\%, CRF 4.3\%, } \\
\text { PVD NR } \%, \text { CVA 3.4\% }\end{array}$ & $\begin{array}{l}\text { Baseline N/A } \\
\text { By NR } \\
\text { Repeat attempts NR }\end{array}$ & $\begin{array}{l}85.5 \% \mathrm{PR} \\
78 \% \mathrm{RR}\end{array}$ & $\begin{array}{l}\text { Follow-up: wide } \\
\text { QOL: NR }\end{array}$ & Poor \\
\hline $\begin{array}{l}\text { Ennker and colleagues }{ }^{20} 2006 \\
(1996-2002)\end{array}$ & $\begin{array}{l}\mathrm{n}=76(>80) \\
\mathrm{n}=427(<80)\end{array}$ & $\mathrm{R}$ & Yes; NHP & No; & $\begin{array}{l}\text { Male 28\%, Urgent NR\%, } \\
\text { Location: Germany } \\
\text { Diabetes } 22 \% \text {, HTN } 53 \% \text {, } \\
\text { Chol 29\% } \\
\text { COPD NR } \% \text {, CRF 14\%, PVD } \\
\text { NR\%, CVA NR\% }\end{array}$ & $\begin{array}{l}\text { Baseline NR } \\
\text { By mail and telephone } \\
\text { Repeat attempts NR }\end{array}$ & $\begin{array}{l}78.7 \% \mathrm{PR} \\
77 \% \mathrm{RR}\end{array}$ & $\begin{array}{l}\text { Follow-up: wide } \\
\text { QoL: narrow }\end{array}$ & Poor \\
\hline $\begin{array}{l}\text { Kolh and colleagues }{ }^{22} 2007 \\
\quad(1992-2004)\end{array}$ & $\mathrm{n}=220(>80)$ & $\mathrm{R}$ & No; own questions & Yes; NYHA & $\begin{array}{l}\text { Male 21\%, Urgent 20\%, } \\
\text { Location: Sweden } \\
\text { Diabetes 12\%, HTN 41\%, } \\
\text { Chol 11\% } \\
\text { CoPD } 5 \% \text {, CRF 4\%, PVD NR } \\
\%, \text { CVA NA } \%\end{array}$ & $\begin{array}{l}\text { Baseline N/A } \\
\text { By clinic visits and annual } \\
\text { letters } \\
\text { Repeat attempts NR }\end{array}$ & $\begin{array}{l}73 \% \mathrm{PR} \\
99 \% \mathrm{RR}\end{array}$ & $\begin{array}{l}\text { Follow-up: narrow } \\
\text { QOL: NR }\end{array}$ & Good \\
\hline $\begin{array}{l}\text { Vicchio and colleagues }{ }^{31} 2007 \\
\text { (1988-2005) }\end{array}$ & $\mathrm{n}=681(>70)$ & $\mathrm{R}$ & Yes; SF-36 & No; & $\begin{array}{l}\text { Male 43.9\%, Urgent 7.6\%, } \\
\text { Location: Iraly } \\
\text { Diabetes 20.1\%, HTN 64\%, } \\
\text { Chol NR\%, } \\
\text { COPD 22.5\%, CRF 3.1\%, } \\
\text { PVD NR } \%, \text { CVA NR } \%\end{array}$ & $\begin{array}{l}\text { Baseline NR } \\
\text { By outpatient review, } \\
\text { ambulatory clinic, } \\
\text { and telephone interview } \\
\text { Repeat attempts NR }\end{array}$ & $\begin{array}{l}84.9 \% \mathrm{PR} \\
96.2 \% \mathrm{RR}\end{array}$ & $\begin{array}{l}\text { Follow-up: wide } \\
\text { QLL: NR }\end{array}$ & Good \\
\hline
\end{tabular}


Vicchio and colleagues ${ }^{53} 2008 \quad \mathrm{n}=147(>70)$

$\mathrm{n}=160(>80)$ (1992-2006)

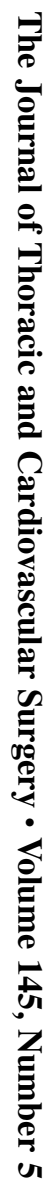

Maillet and colleagues ${ }^{8} 2009 \quad \mathrm{n}=84(>80)$

(1998-2001)

$$
\mathrm{n}=84(>80)
$$

Aoyagi and colleagues ${ }^{18} 2010 \quad \mathrm{n}=60(>80)$ (1994-2008)

$\mathrm{n}=1387(<80)$

Ferrari and colleagues ${ }^{15} 2010 \quad \mathrm{n}=124(>80)$

(1990-2005)

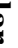

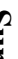

范

2010 (2005-2007)

$\mathrm{n}=154(>80)$

Spaziano and colleague $\mathrm{s}^{30}$ 2010 (2003-2006)

$\mathrm{n}=161(>80)$
No; own questions

Yes; NYHA

No;

No; own question

No;

Male $19.7 \%$, Urgent NR $\%$,

Location: Italy

Diabetes $21.2 \%$

Chol NR\%

Prosthesis/mechanical

Prosthesis:

Male $45.6 / 41.3 \%$, Urgent: NR

$\%$, Location: Italy

Diabetes $26.5 / 23.9 \%$, HTN

66.2/66.3\%, Chol NR $\%$

COPD $32.4 / 34.8 \%$, CRF $2.9 /$

4.3\%, PVD NR $\%$, CVA

$\mathrm{NR} \%$

\section{Male $37 \%$, Urgent NR $\%$,}

Location: France

Diabetes NR $\%$, HTN NR $\%$,

Chol NR\%

COPD $22.6 \%$, CRF $16.7 \%$,

PVD $20.2 \%$, CVA NR $\%$

Male 38.3\%, Urgent 16.7\%,

Location: Japan

Diabetes $11.7 \%$, HTN $63.3 \%$,

Chol \%

OPD $13.3 \%$, CRF $6.7 \%$

PVD $20.0 \%$, CVA $26.7 \%$

R No; own questions

Yes; NYHA

Male $37 \%$, Urgent $3.0 \%$,

Location: Switzerland

Diabetes $10 \%$, HTN $57 \%$,

Chol $23 \%$

COPD NR $\%$, CRF 22\%, PVD

NR $\%$, CVA NR $\%$

Male $33.8 \%$, Urgent NR\% Location: Austria

Diabetes $30.3 \%$, HTN NR $\%$,

Chol NR\%

COPD $54.9 \%$, CRF $38.7 \%$,

PVD $14.7 \%$, CVA $15.1 \%$

Yes; SF-12
MLHFQ

Yes; NYHA

\section{Male $50 \%$, Urgent NR $\%$,}

Location: Canada

Location: Canada
Diabetes NR\%, HTN NR\%,

By mail and telephon

Repeat attempts NR

Chol NR\%

COPD NR $\%$, CRF NR $\%$,

PVD NR\%, CVA NR\%
Baseline NR

Baseline NR

$97.8 \% \mathrm{PR}$

outpatient review and

$100 \%$ RR

Follow-up: wide

QOL: NR

Poor

Repeat attempts NR

Baseline NR

y institutional ambulatory

$75.6 \% \mathrm{PR}$

$97.6 \% \mathrm{RR}$

Follow-up: wid

QOL: NR

Good

Repeat attempts NR

Baseline N/A

By telephone interview

$66.7 \% \mathrm{PR}$

NR\% RR

Follow-up: wide

QOL: NR

Baseline N/A

By review of hospital record

direct patient contact, or

mail

Repeat attempts NR

Baseline N/A

By NR

Repeat attempts NR

$94.4 \%$ PR

Follow-up: NR

QOL: NR

Poor

seline N/A

By telephone

Repeat attempts NR

$81.8 \%$

$\mathrm{NR} \% \mathrm{RR}$

Follow-up: N

QOL: NR

$82.6 \% \mathrm{PR}$

$64.4 \% \mathrm{RR}$

Follow-up: modera

QOL: wide

Markou and colleague ${ }^{24} 2011$

Yes; EuroQO

PDF not sourced* 


\section{• TABLE 2. Continued}

\begin{tabular}{|c|c|c|c|c|c|c|c|c|c|}
\hline \multirow[b]{2}{*}{ Author year (study period) } & \multirow[b]{2}{*}{ Patients } & \multirow[b]{2}{*}{ Study design } & \multicolumn{4}{|c|}{ Methodological quality } & \multicolumn{2}{|c|}{ Precision } & \multirow{2}{*}{$\begin{array}{l}\text { Overal } \\
\text { vstudy } \\
\text { quality } \\
\end{array}$} \\
\hline & & & $\begin{array}{c}\begin{array}{c}\text { Validated HRQOL } \\
\text { instrument }\end{array} \\
\end{array}$ & $\begin{array}{c}\begin{array}{c}\text { Cardiac-specific } \\
\text { measures }\end{array} \\
\end{array}$ & Patient demographics & $\begin{array}{c}\text { Method of follow-up and } \\
\text { HRQOL assessment }\end{array}$ & $\begin{array}{c}\text { Follow-up } \\
\text { consistency }\end{array}$ & $\begin{array}{c}\text { Range/CI/SE/SD } \\
\text { of results }\end{array}$ & \\
\hline $\begin{array}{l}\text { Nikolaidis and colleagues }{ }^{26} \\
2011 \text { (2000-2008) }\end{array}$ & $\mathrm{n}=345(>80)$ & $\mathrm{R}$ & No; & Yes; NYHA & $\begin{array}{l}\text { Male } 65.5 \% \text {, Urgent } 45.5 \% \text {, } \\
\text { Location: UK } \\
\text { Diabetes } 6.9 \% \text {, HTN NR } \% \text {, } \\
\text { Chol NR } \% \\
\text { COPD } 11.6 \% \text {, CRF } 3.4 \% \text {, } \\
\text { PVD 3.7\%, CVA 4.9\% }\end{array}$ & $\begin{array}{l}\text { Baseline N/A } \\
\text { By mail } \\
\text { Repeat attempts NR }\end{array}$ & $\begin{array}{l}81 \% \mathrm{PR} \\
62 \% \mathrm{RR}\end{array}$ & $\begin{array}{l}\text { Follow-up: wide } \\
\text { QOL: NR }\end{array}$ & Poor \\
\hline $\begin{array}{l}\text { Oliveira and colleagues }{ }^{28} 2012 \\
\quad \text { (2002-2006) }\end{array}$ & $\mathrm{n}=144(>75)$ & $\mathrm{R}$ & No; own questions & No; & $\begin{array}{l}\text { Male 38.6\%, Urgent 28.1\%, } \\
\text { Location: Portugal } \\
\text { Diabetes } 18.4 \% \text {, HTN } 63.2 \% \text {, } \\
\text { Chol 42.3\% } \\
\text { COPD NR } \% \text {, CRF } 57 \% \text {, PVD } \\
\text { NR\%, CVA NR } \%\end{array}$ & $\begin{array}{l}\text { Baseline N/A } \\
\text { By telephone interview with } \\
\text { patient or next of kin, } \\
\text { or at outpatient clinic } \\
\text { Repeat attempts NR }\end{array}$ & $\begin{array}{l}76.3 \% \mathrm{PR} \\
99.1 \% \mathrm{RR}\end{array}$ & $\begin{array}{l}\text { Follow-up: wide } \\
\text { QOL: NR }\end{array}$ & Poor \\
\hline $\begin{array}{l}\text { Reynolds and colleagues }^{54} \\
2012(2007-2009)\end{array}$ & $\begin{array}{l}\mathrm{n}=216 \\
(\mathrm{TF}) \\
\mathrm{n}=84 \\
(\mathrm{TA})\end{array}$ & $\mathrm{P}$ & $\begin{array}{l}\text { Yes; SF-12 } \\
\text { EQ-5D }\end{array}$ & Yes; KCCQ & $\begin{array}{l}\text { Cohort TF/TA: } \\
\text { Male 55.6\%/59.5\%, Urgent } \\
\text { NR\%, Location: United } \\
\text { States } \\
\text { Diabetes NR\%, HTN NR } \% \text {, } \\
\text { Chol NR } \% \\
\text { COPD 7.4\%/7.1\%, CRF NR } \\
\% \text {, PVD 35.7\% } / 62.7 \%, \\
\text { CVA 22.7\% } / 29.8 \%\end{array}$ & $\begin{array}{l}\text { Baseline performed } \\
\text { By scheduled follow-up visits } \\
\text { or by mail } \\
\text { Repeat attempts N/A }\end{array}$ & $\begin{array}{l}89.8 \% \text { PR } \\
>80 \% \text { RR }\end{array}$ & $\begin{array}{l}\text { Follow-up: N/A } \\
\text { QOL: wide }\end{array}$ & Excellent \\
\hline $\begin{array}{l}\text { Vicchio and colleagues }{ }^{32} 2012 \\
\quad(1991-2010)\end{array}$ & $\mathrm{n}=520(>70)$ & $\mathrm{R}$ & Yes; SF-36 & $\mathrm{No}$ & $\begin{array}{l}\text { Group A/B: } \\
\text { Male } 42.6 / 64 \% \text {, Urgent NR } \% \text {, } \\
\text { Location: Italy }\end{array}$ & $\begin{array}{l}\text { Baseline NR } \\
\text { By institutional ambulatory } \\
\quad \text { activities } \\
\text { Repeat attempts NR } \\
\end{array}$ & $\begin{array}{l}96.9 \% \mathrm{PR} \\
98.3 \% \mathrm{RR}\end{array}$ & $\begin{array}{l}\text { Follow-up: wide } \\
\text { QOL: NR }\end{array}$ & Good \\
\hline
\end{tabular}


TABLE 3. Results of studies reviewed

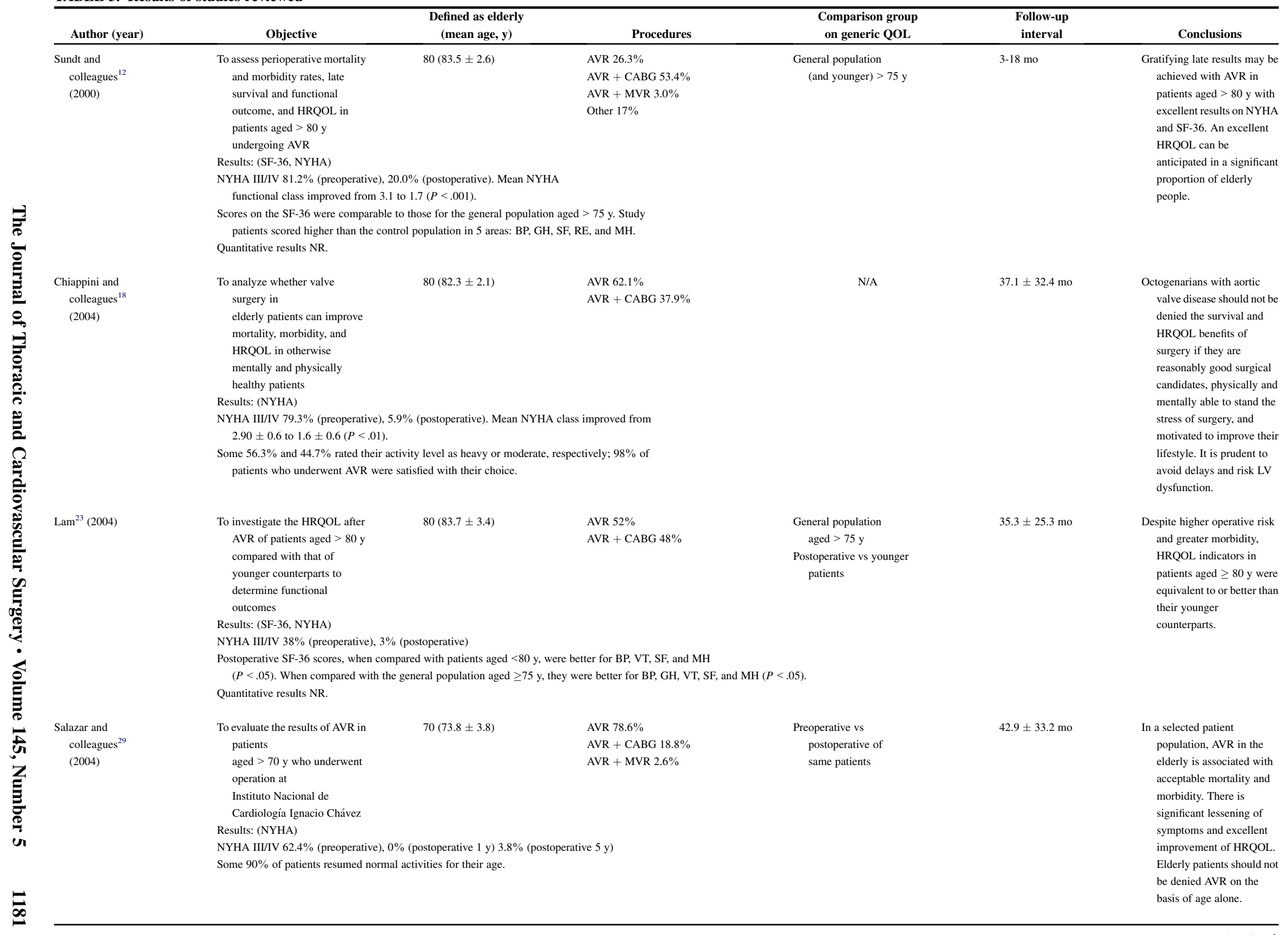


TABLE 3. Continued

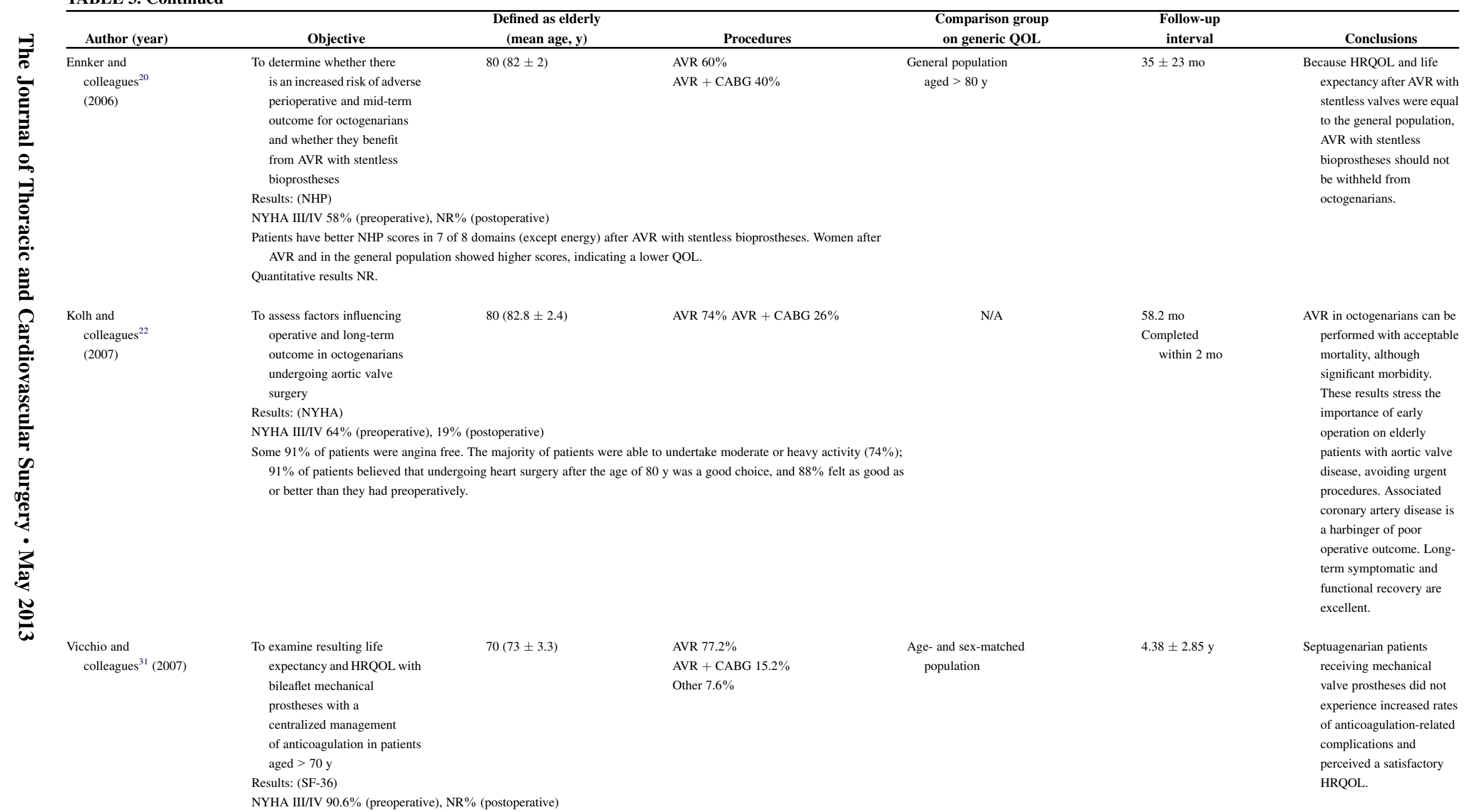




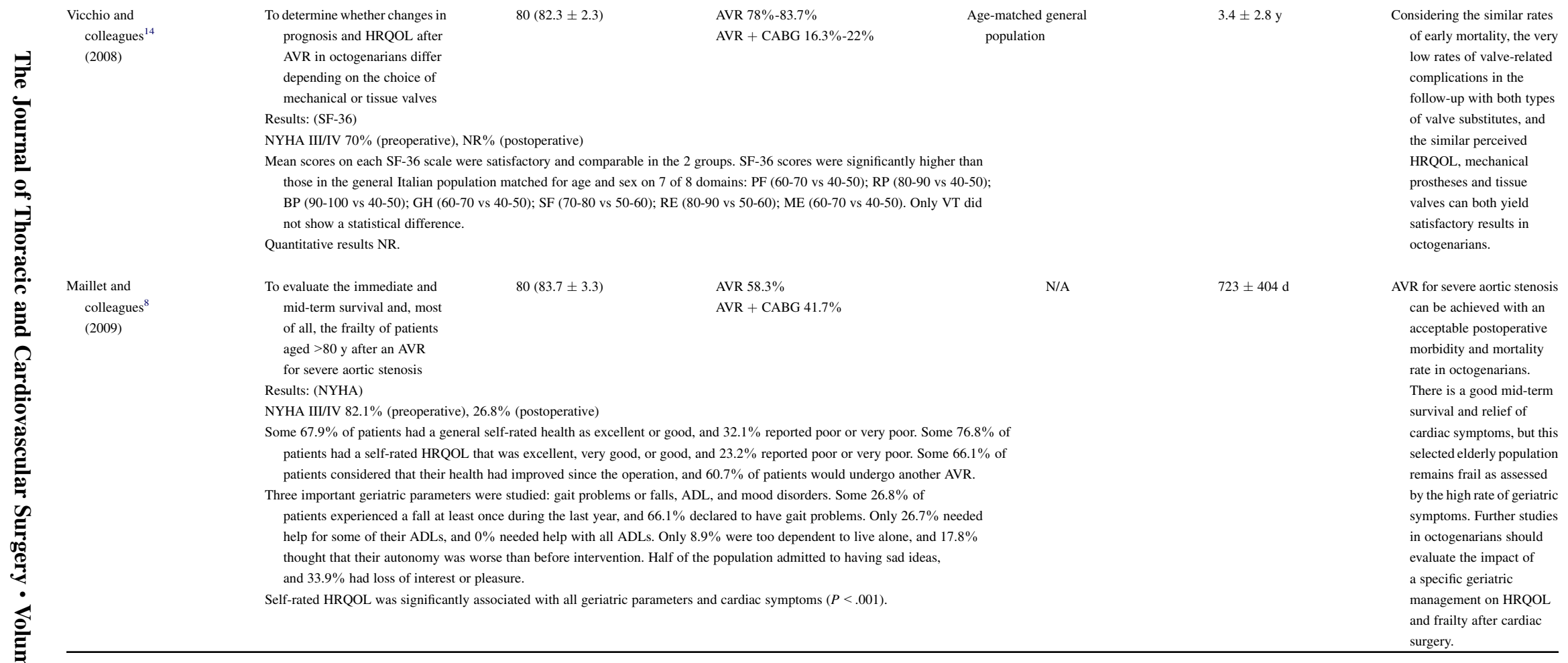




\section{•}

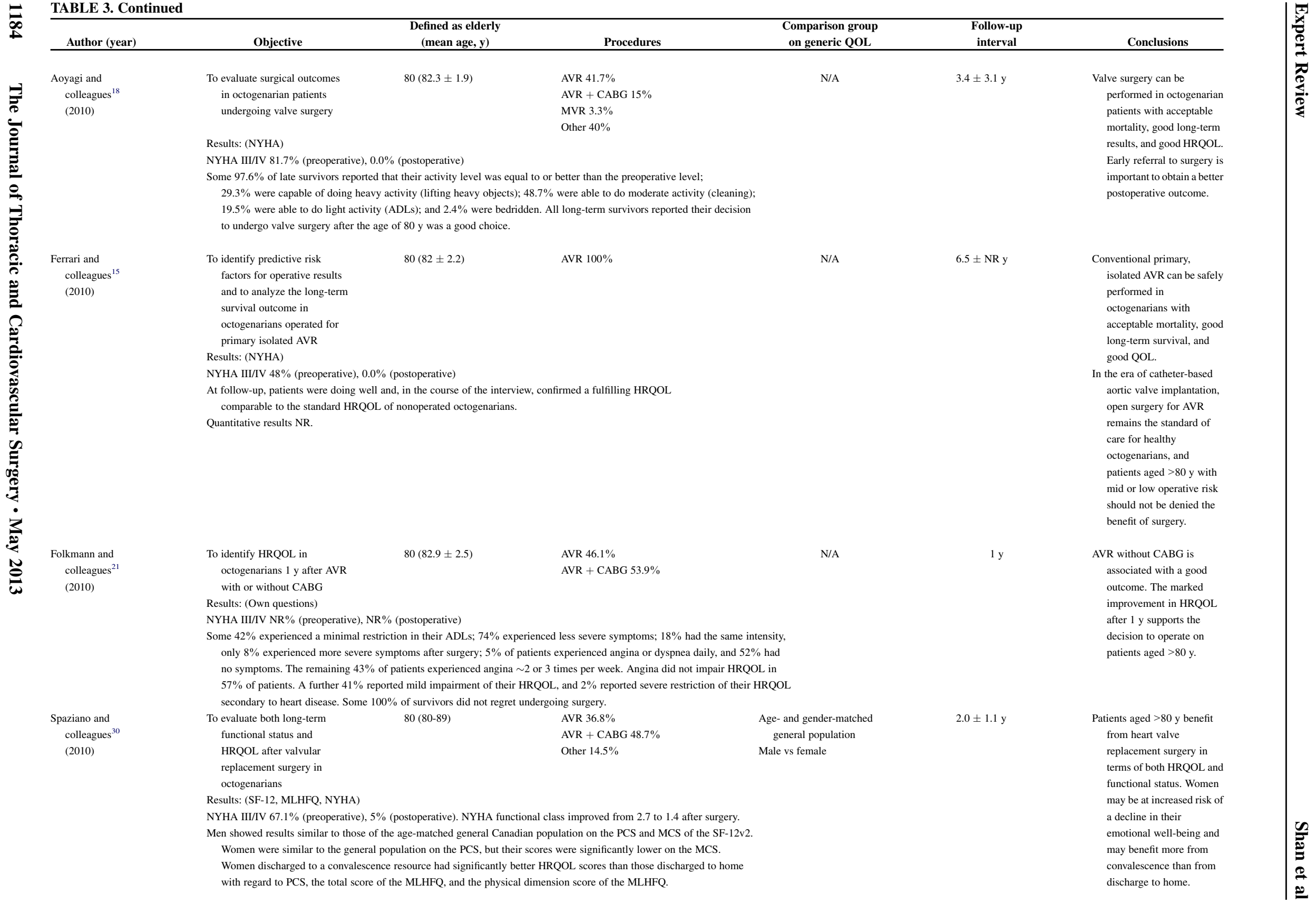


Markou and

colleagues $^{24}$

colleagu
(2011)

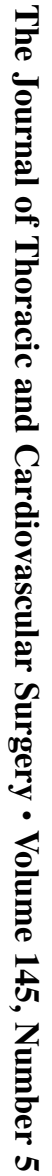

官

攵

Nikolaidis and

colleagues $^{26}$
To investigate changes of

AVR $40.4 \%$

Preoperative vs postoperative of

same patients

CABG $51.6 \%$

aged $>70$

Results: (EuroQOL)

NYHA III/IV \% (preoperative), \% (postoperative)

At 1 y postoperatively, the EQ-5D index of the CABG group shows a significant increase, whereas that of the AVR group

does not; however, the EQ-VAS registration shows a significant increase for both the CABG group and AVR group.

The AVR group improved on pain and discomfort item. The CABG group improved in mobility, pain and discomfort, and anxiety.

PDF document unable to be sourced.
To analyze the early and long-
$80(82.9+2.3)$

erm mortality, morbidity,

and $\mathrm{HRQOL}$ in patients

BG $51.6 \%$

Other $2.9 \%$

AVR alone or combined with

CABG

Results: (NYHA)

NYHA IU/IV 56\% (preoperative) $12 \%$ (postoperative)

The majority of the patients were asymptomatic, whereas $13 \%$ were experiencing angina. Some $82 \%$ had independent personal care; $88.3 \%$ had positive feelings about life; and $82 \%$ were happy with their decision to undertake the operation.

$\begin{array}{lll}\text { To review the long-term survival, } & 75(78.5 \pm 2.5) & \text { AVR } \\ \text { autonomy, and HRQOL of } & & \text { AVR }+ \text { CABG } \\ \text { elderly patients undergoing } & \text { AVR }+ \text { MVR } \\ \text { AVR } & \text { Other }\end{array}$

Its: (Barthel's Index)

Some $89.6 \%$ of patients were autonomous (BI score $\geq 85$ ), whereas a dependent status (BI score $\leq 60$ ) was observed in

$5.2 \% ; 93.5 \%$ of patients confirmed having had an improvement in their HRQOL with AVR, and the remaining recognized that

they had no additional benefit regarding their QOL.
In elderly patients, HRQOL strongly increases after CABG and AVR; however, he improvement of

nctional and social

HRQOL is less for patients

undergoing AVR

compared with CABG.

VR can be undertaken with excellent results in octogenarians, and the current risk is significantly lower than what is

predicted with

conventional risk-scoring

systems. Patients of

advanced age should not

necessarily be excluded from being candidates for AVR.

At follow-up, most patients achieved improvement of HRQOL and remained utonomous. These results stress that excellent longrm outcomes with AVR can be achieved in appropriately selected ederly patients.

(continued) 


\section{$\varpi$ TABLE 3. Continued}

Author (year)

Objective

Defined as elderly

Comparison group

Follow-up

interval

Conclusions

$\begin{array}{ccc}\text { Reynolds and } & \text { To compare health status and } & 80 \\ \text { colleagues }^{54} & \text { HRQOL outcomes for } & \text { TF }(84.6 \pm 6.5 \\ \text { (2012) } & \text { patients with severe aortic } & \text { TA }(83.2 \pm 5.9 \\ & \text { stenosis and high surgical } & \\ \text { risk treated with transcatheter } & \text { or surgical AVR } \\ \text { Results: (SF-12, EQ-5D, KCCQ) } & \\ & \text { NYHA III/IV NR\% (preoperative), NR\% (postoperative) }\end{array}$

Procedures

Transfemoral transcatheter AVR

Transapical transcatheter AVR

$0,1,6,12 \mathrm{mo}$

Both transcatheter and

surgical AVR groups

experienced substantial

improvements at $1 \mathrm{y}$. This

is despite patients being in

the highest $5 \%$ of surgical

NYHA III/IV NR\% (preoperative), NR\% (postoperative)

There are great, highly statistically significant, and clinically meaningful HROOL improvements at 6 and $12 \mathrm{mo}$.

TF cohort: There are significant benefits for KCCQ summary $(P<.001)$, KCCQ physical limitation $(P<.001)$,

KCCQ total symptoms $(P<.001)$, KCCQ QOL $(P<.001)$, KCCQ social limitations $(P<.001)$, SF-12 physical $(P<.001)$,

SF-12 mental $(P=.001)$, and EQ-5D utility $(P<.001)$ scores up to $12 \mathrm{mo}$.

TA cohort: There are significant benefits for KCCQ summary $(P<.001)$, KCCQ physical limitation $(P=.008)$, KCCQ total symptom

risk according to the

Society of Thoracic

Surgeon Series.

Transfemoral

transcatheter AVR may be

associated with a short-

term advantage compared

$(P<.001)$, KCCQ
scores up to 12 mo.

Please refer to original article for detailed quantititive results.

To evaluate the impact on $70(74.2 \pm 3.6)$

$\begin{array}{ll}70(742 \pm 3.6) & \text { AVR } 78.1 \%\end{array}$

survival and HRQOL of $\quad$ AVR + CABG $21.9 \%$

Age- and sex-matched general

with surgery.

CABG associated with AVR

population

Associated CABG determines a significant increase of hospital mortality in the elderly undergoing AVR Survivors did not show

differences in long-term

Results: (SF-36)

NYHA III/IV A: 74\% B: $74.5 \%$ (preoperative), NR\% (postoperative)

Elderly patients achieved SF-36 scores higher than the general age- and sex-matched Italian population matched population in all domains

outcome and HRQOL

of associated $\mathrm{CABG}$

$(P<.001)$ : (group A/group B vs general population): $\mathrm{PF}$ (66.8/66.6 vs 47.4), RP (86 4/85.8 vs 47.2). BP (93.2/92.7 vs 48.7), GH

(64.5/65.2 vs 42.2), VT (62.4/61.8 vs 44.2), $\mathrm{SF}(80.8 / 81.3$ vs 59.5$)$, RE (90.7/91.2 vs 52.2$)$, and $\mathrm{MH}(69.8 / 70.6$ vs 53.3$)$.

QOL, Quality of life; $H R Q O L$, health-related quality of life; $A V R$, aortic valve replacement; $C A B G$, coronary artery bypass grafting; $M V R$, mitral valve replacement; $N Y H A$, New York Heart Association; $S F-36$, Medical Outcomes
Survey Short Form $36 ; S F-12$, Medical Outcomes Survey Short Form $12 ; B P$, bodily pain; $G H$, general health; $S F$, social functioning; $R E$, role emotional; $M H$, mental health; $V T$, vitality; $L V$, left ventricular; $N H P$, Nottingham Health Profile; $P F$, physical functioning; $R P$, role physical; $N R$, not recorded; $N / A$, not applicable; $A D L$, activities of daily living; $M L H F Q$, Minnesota Living with Heart Failure Questionnaire; $P C S$, physical component summary score; $M C S$, 
TABLE 4. Early mortality in elderly patients after aortic valve replacement

\begin{tabular}{|c|c|c|c|c|}
\hline Study & Year & Overall early mortality & Isolated AVR & AVR + CABG \\
\hline \multicolumn{5}{|l|}{ Studies included in this review } \\
\hline Sundt and colleagues ${ }^{12}$ & 2000 & $11 \%$ & $8.6 \%$ & $14.1 \%$ \\
\hline Chiappini and colleagues ${ }^{19}$ & 2004 & $8.5 \%$ & - & - \\
\hline Lam and Hendry ${ }^{23}$ & 2004 & $8.6 \%$ & $6.7 \%$ & $10.7 \%$ \\
\hline Salazar and colleagues ${ }^{29}$ & 2004 & $14.5 \%$ & - & $9.1 \%$ \\
\hline Ennker and colleagues ${ }^{20}$ & 2006 & $6.6 \%$ & - & - \\
\hline Kolh and colleagues $^{22}$ & 2007 & $13 \%$ & $9 \%$ & $24 \%$ \\
\hline Vicchio and colleagues ${ }^{31}$ & 2007 & $11.8 \%$ & - & - \\
\hline Vicchio and colleagues ${ }^{53}$ & 2008 & $8.8 \%$ & - & - \\
\hline Vicchio and colleagues ${ }^{14}$ & 2008 & $8.8 \%$ & $8.5 \%$ & $10 \%$ \\
\hline Maillet and colleagues ${ }^{8}$ & 2009 & $16.7 \%$ & $10.2 \%$ & $25.7 \%$ \\
\hline Aoyagi and colleagues ${ }^{18}$ & 2010 & $13.3 \%$ & - & - \\
\hline Ferrari and colleagues ${ }^{15}$ & 2010 & $5.6 \%$ & - & - \\
\hline Folkmann and colleagues ${ }^{21}$ & 2010 & $7.8 \%$ & $6.8 \%$ & $8.8 \%$ \\
\hline Spaziano and colleagues ${ }^{30}$ & 2010 & $5.6 \%$ & - & - \\
\hline Markou and colleagues ${ }^{24}$ & 2011 & - & - & - \\
\hline Nikolaidis and colleagues $^{26}$ & 2011 & $4.9 \%$ & $4.3 \%$ & $5.4 \%$ \\
\hline Oliveira $^{28}$ & 2012 & $2.7 \%$ & - & - \\
\hline Reynolds and colleagues $^{54}$ & 2012 & - & - & - \\
\hline Vicchio and colleagues ${ }^{32}$ & 2012 & - & $7.8 \%$ & $15.2 \%$ \\
\hline \multicolumn{5}{|l|}{ Meta-analysis } \\
\hline Vasques and colleagues ${ }^{2}$ & 2012 & - & $6.7 \%$ & - \\
\hline
\end{tabular}

Vasques and colleagues ${ }^{2}$ recently performed a metaanalysis of 13,216 patients that showed a low overall pooled postoperative mortality of $6.7 \%$ in octogenarians undergoing isolated AVR, especially in contemporary series $5.8 \%$ for studies published from 2000 to 2006 and $7.5 \%$ for studies published from 1982 to 1999). Given low levels of early mortality and excellent long-term survival, ${ }^{2,10,13,57}$ as well as excellent HRQOL, delay or exclusion from surgical intervention based solely on age may deny patients from receiving best practice care. The risk of surgery is better judged by the presence of significant comorbidities, such as renal failure, stroke, and use of an intra-aortic balloon pump. ${ }^{13}$ Careful selection of patients based on these factors rather than age results in good operative outcomes and provides these patients the chance at significant HRQOL benefits. Some of the important factors are physical and mental ability to withstand the stress of surgery and motivation to improve postoperative lifestyle and participate in rehabilitation. ${ }^{19}$

Transcatheter aortic valve implantation has been evaluated for HRQOL benefits, especially in high-risk surgical patients. ${ }^{58-60}$ Reynolds and colleagues ${ }^{54}$ compared the transcatheter approach with conventional surgical AVR in the highest risk surgical patients according to the Society of Thoracic Surgeons Series. Both transcatheter implantation and surgical AVR led to highly statistically significant and clinically meaningful HRQOL benefits. However, data remain limited, and more time is required before this procedure becomes an established treatment modality for elderly patients.

The focus is no longer purely about prolonging life, but rather about improving the HRQOL, which is now a primary intention of surgery in elderly patients. Elderly patients themselves are frequently concerned about their postoperative HRQOL, such as their social and mental function. ${ }^{17}$ Information about expected HRQOL allows these patients to have realistic expectations on physical, functional, emotional, and mental welfare. This review demonstrates that there is increasing evidence showing worthwhile gains in regard to HRQOL after AVR in selected elderly patients.

The patients from the 19 articles reviewed span a wide range of developed nations: United States, Canada, Germany, France, Italy, Switzerland, Sweden, Austria, United Kingdom, Australia, Japan, Mexico, and Portugal. Thus, the results of this systematic review are applicable to all developed countries. Both elderly patients and their families can be more confident about the benefits of undergoing AVR when it is required. Moreover, performing surgery in the elderly seems to be cost-effective. ${ }^{24}$ Larger prospective trials also will be required to further clarify the findings of this systematic review. Nonetheless, given the increasing evidence demonstrating good HRQOL after AVR and a rapidly increasing elderly population, it is imperative that healthcare providers can now more confidently provide AVR to elderly patients. 


\section{Review Limitations}

We aimed to minimize reporting bias with a comprehensive search of the literature for all studies that meet our eligibility criteria. Despite using multiple online and hospital databases, as well as directly e-mailing authors, there was incomplete retrieval of identified research for 1 article. ${ }^{24}$ In addition, publication bias may have occurred given that only published data were assessed.

We acknowledge that the level of evidence of this systematic review cannot exceed the level of evidence of the current literature. However, this systematic review adds substantially to the currently available evidence for elderly patients being considered for AVR and builds on the conclusions of nonsystematic narrative reviews. ${ }^{27}$

\section{Future Direction}

This systematic review revealed a heterogeneous data set that is difficult to compare and interpret. The subjective nature of HRQOL means a consistent method of investigation is required. Our recommendations for future studies on HRQOL after AVR are outlined next.

The most important method of accurately determining HRQOL is by using previously validated, reliable, and reproducible HRQOL instruments, such as the SF-36. The study should have a prospective design with predetermined follow-up time points to minimize bias, show HRQOL progression over time, and allow comparison between studies. Consistent measurements should be performed at baseline; 1 and 6 months; and 1, 2, 3, 4, 5, and 10 years. Telephone interviews are preferable, and repeated attempts at contact to minimize loss to follow-up are advisable. Elderly patients should have their preoperative baseline HRQOL scores compared with postoperative scores at each time point. This review demonstrates the benefit of comparing baseline and postoperative HRQOL scores with an age-matched general population. Because it is unethical to deny patients surgery if they are fit for surgery, it may be possible to compare patients who received surgery and those who refused or opted for nonsurgical interventions. To highlight that HRQOL results are not dependent on age, the change scores between baseline and postoperative measurements of older patients can be compared with the change scores of younger patients. The caveat is that younger patients tend to have accumulated less comorbidities, so the effect of age can only be ascertained if patients are matched for comorbidities. Patients also should be relatively well matched for other characteristics, especially for age and urgency of operation. Because urgent cardiac operations are associated with worse outcomes and mortality, it would be ideal to conduct studies purely on patients undergoing elective surgery, who are more likely to receive AVR in the first place. Finally, multicenter involvement should be organized to increase patient numbers and minimize bias from single-center studies.

\section{CONCLUSIONS}

The main findings of this systematic review are that elderly patients have (1) improvement in cardiac symptoms after AVR, (2) equal or better HRQOL compared with an age-matched general population, (3) equivalent or superior HRQOL compared with younger patients who underwent AVR, and (4) significant functional gains after surgery. We highlight the positive impact of AVR on HRQOL of elderly patients. This systematic review should encourage doctors to evaluate potential patients for AVR surgery on the basis of their comorbidities rather than using age as a precluding factor. This review is complete for the current literature, but we emphasize that in the absence of large randomized controlled trials, this recommendation must be considered in conjunction with clinical decision-making tailored to each patient.

\section{References}

1. World Population Prospects: The 2010 Revision. New York: UN Population Division; 2011.

2. Vasques F, Messori A, Lucenteforte E, Biancari F. Immediate and late outcome of patients aged 80 years and older undergoing isolated aortic valve replacement: a systematic review and meta-analysis of 48 studies. Am Heart J. 2012;163: 477-85.

3. Wasywich CA, Ruygrok PN, West TM, Haydock DA. Extended follow up after isolated aortic valve replacement in the elderly. Heart Lung Circ. 2003;12:103-7.

4. Stewart BF, Siscovick D, Lind BK, Gardin JM, Gottdiener JS, Smith VE, et al. Clinical factors associated with calcific aortic valve disease. Cardiovascular Health Study. J Am Coll Cardiol. 1997;29:630-4.

5. Novaro GM, Katz R, Aviles RJ, Gottdiener JS, Cushman M, Psaty BM, et al. Clinical factors, but not C-reactive protein, predict progression of calcific aortic-valve disease: the Cardiovascular Health Study. J Am Coll Cardiol. 2007;50:1992-8.

6. Nkomo VT, Gardin JM, Skelton TN, Gottdiener JS, Scott CG, EnriquezSarano M. Burden of valvular heart diseases: a population-based study. Lancet. 2006;368:1005-11.

7. Chrysohoou C, Tsiachris D, Stefanadis C. Aortic stenosis in the elderly: challenges in diagnosis and therapy. Maturitas. 2011;70:349-53.

8. Maillet JM, Somme D, Hennel E, Lessana A, Saint-Jean O, Brodaty D. Frailty after aortic valve replacement (AVR) in octogenarians. Arch Gerontol Geriatr. 2009;48:391-6.

9. Sharma UC, Barenbrug P, Pokharel S, Dassen WR, Pinto YM, Maessen JG. Systematic review of the outcome of aortic valve replacement in patients with aortic stenosis. Ann Thorac Surg. 2004;78:90-5.

10. Kojodjojo P, Gohil N, Barker D, Youssefi P, Salukhe TV, Choong A, et al. Outcomes of elderly patients aged 80 and over with symptomatic, severe aortic stenosis: impact of patient's choice of refusing aortic valve replacement on survival. QJM. 2008;101:567-73.

11. Bouma BJ, van Den Brink RB, van Der Meulen JH, Verheul HA, Cheriex EC, Hamer HP, et al. To operate or not on elderly patients with aortic stenosis: the decision and its consequences. Heart. 1999;82:143-8.

12. Sundt TM, Bailey MS, Moon MR, Mendeloff EN, Huddleston CB, Pasque MK, et al. Quality of life after aortic valve replacement at the age of $>80$ years. Circulation. 2000;102:III70-4.

13. Melby SJ, Zierer A, Kaiser SP, Guthrie TJ, Keune JD, Schuessler RB, et al. Aortic valve replacement in octogenarians: risk factors for early and late mortality. Ann Thorac Surg. 2007;83:1651-7.

14. Vicchio M, Della Corte A, De Santo LS, DeFeo M, Caianiello G, Scardone M, et al. Tissue versus mechanical prostheses: quality of life in octogenarians. Ann Thorac Surg. 2008;85:1290-5.

15. Ferrari E, Tozzi P, Hurni M, Ruchat P, Stumpe F, von Segesser LK. Primary isolated aortic valve surgery in octogenarians. Eur J Cardiothorac Surg. 2010;38: 128-33.

16. Mittermair RP, Muller LC. Quality of life after cardiac surgery in the elderly. $J$ Cardiovasc Surg (Torino). 2002;43:43-7. 
17. Chaturvedi RK, Blaise M, Verdon J, Iqbal S, Ergina P, Cecere R, et al. Cardiac surgery in octogenarians: long-term survival, functional status, living arrangements, and leisure activities. Ann Thorac Surg. 2010;89:805-10.

18. Aoyagi S, Fukunaga S, Arinaga K, Tomoeda H, Akasu K, Ueda T. Heart valve surgery in octogenarians: operative and long-term results. Heart Vessels. 2010; 25:522-8.

19. Chiappini B, Camurri N, Loforte A, Di Marco L, Di Bartolomeo R, Marinelli G. Outcome after aortic valve replacement in octogenarians. Ann Thorac Surg. 2004;78:85-9.

20. Ennker J, Dalladaku F, Rosendahl U, Ennker IC, Mauser M, Florath I. The stentless freestyle bioprosthesis: impact of age over 80 years on quality of life, perioperative, and mid-term outcome. J Card Surg. 2006;21:379-85.

21. Folkmann S, Gorlitzer M, Weiss G, Harrer M, Thalmann M, Poslussny P, et al. Quality-of-life in octogenarians one year after aortic valve replacement with or without coronary artery bypass surgery. Interact Cardiovasc Thorac Surg. 2010;11:750-3.

22. Kolh P, Kerzmann A, Honore C, Comte L, Limet R. Aortic valve surgery in octogenarians: predictive factors for operative and long-term results. Eur J Cardiothorac Surg. 2007;31:600-6.

23. Lam BK, Hendry PJ. Patients over 80 years: quality of life after aortic valve replacement. Age Ageing. 2004;33:307-9.

24. Markou AL, Selten K, Krabbe PF, Noyez L. Quality of life one year post myocardial revascularization and aortic valve replacement in patients aged 70 year or older. J Cardiovasc Surg (Torino). 2011;52:601-7.

25. Mullany CJ. Aortic valve surgery in the elderly. Cardiol Rev. 2000;8:333-9.

26. Nikolaidis N, Pousios D, Haw MP, Kaarne M, Barlow CW, Livesey SA, et al. Long-term outcomes in octogenarians following aortic valve replacement. $J$ Card Surg. 2011;26:466-71.

27. Nugteren LB, Sandau KE. Critical review of health-related quality of life studies of patients with aortic stenosis. J Cardiovasc Nurs. 2010;25:25-39.

28. Oliveira SM, Correia AS, Paiva M, Goncalves A, Pereira M, Alves E, et al. Longterm survival, autonomy, and quality of life of elderly patients undergoing aortic valve replacement. J Card Surg. 2012;27:20-3.

29. Salazar E, Torres J, Barragan R, Lopez M, Lasses LA. Aortic valve replacement in patients 70 years and older. Clin Cardiol. 2004;27:565-70.

30. Spaziano M, Carrier M, Pellerin M, Choiniere M. Quality of life following heart valve replacement in the elderly. J Heart Valve Dis. 2010;19:524-32.

31. Vicchio M, Della Corte A, De Feo M, Santarpino G, De Santo LS, Romano G, et al. Quality of life after implantation of bileaflet prostheses in elderly patients: an anticoagulation work group experience. Ann Thorac Surg. 2007; 84:459-65.

32. Vicchio M, Feo MD, Giordano S, Provenzano R, Cotrufo M, Nappi G. Coronary artery bypass grafting associated to aortic valve replacement in the elderly: survival and quality of life. J Cardiothorac Surg. 2012;7:13.

33. Wu Y, Grunkemeier GL, Starr A. The value of aortic valve replacement in elderly patients: an economic analysis. J Thorac Cardiovasc Surg. 2007; 133:603-7.

34. Iung B, Cachier A, Baron G, Messika-Zeitoun D, Delahaye F, Tornos P, et al. Decision-making in elderly patients with severe aortic stenosis: why are so many denied surgery? Eur Heart J. 2005;26:2714-20.

35. Bonow RO, Carabello BA, Kanu C, de Leon AC Jr, Faxon DP, Freed MD, et al. ACC/AHA 2006 guidelines for the management of patients with valvular heart disease: a report of the American College of Cardiology/American Heart Association Task Force on Practice Guidelines (writing committee to revise the 1998 Guidelines for the Management of Patients With Valvular Heart Disease): developed in collaboration with the Society of Cardiovascular Anesthesiologists: endorsed by the Society for Cardiovascular Angiography and Interventions and the Society of Thoracic Surgeons. Circulation. 2006;114: e84-231.

36. Wright RW, Brand RA, Dunn W, Spindler KP. How to write a systematic review. Clin Orthop Relat Res. 2007;455:23-9.

37. Moher D, Liberati A, Tetzlaff J, Altman DG. Preferred reporting items for systematic reviews and meta-analyses: the PRISMA statement. PLoS Med. 2009; 6:e1000097.

38. Constitution of the World Health Organization. In: World Heath Organization. Handbook of Basic Documents. 5th ed. Geneva: Palais des Nations; 1952:3-52.
39. Testa MA, Simonson DC. Assessment of quality-of-life outcomes. $N$ Engl J Med 1996;334:835-40.

40. Dolgin M. Nomenclature and Criteria for Diagnosis of Diseases of the Heart and Great Vessels. 9th ed. Boston, MA: Little, Brown and Co; 1994

41. Supino PG, Borer JS, Franciosa JA, Preibisz JJ, Hochreiter C, Isom OW, et al. Acceptability and psychometric properties of the Minnesota Living With Heart Failure Questionnaire among patients undergoing heart valve surgery: validation and comparison with SF-36. J Card Fail. 2009;15:267-77.

42. Green CP, Porter CB, Bresnahan DR, Spertus JA. Development and evaluation of the Kansas City Cardiomyopathy Questionnaire: a new health status measure for heart failure. J Am Coll Cardiol. 2000;35:1245-55.

43. Group W. Study Protocol for the World Health Organisation project to develop a quality of life assessment instrument (WHOQOL). Qual Life Res. 1993;2: 153-9.

44. Bullinger M. [Assessment of health related quality of life with the SF-36 Health Survey]. Rehabilitation (Stuttg). 1996;35:XVII-XXVII; quiz XXVII-XXIX

45. Failde I, Ramos I. Validity and reliability of the SF-36 Health Survey Questionnaire in patients with coronary artery disease. J Clin Epidemiol. 2000;53: 359-65.

46. Hayes V, Morris J, Wolfe C, Morgan M. The SF-36 health survey questionnaire: is it suitable for use with older adults? Age Ageing. 1995;24:120-5.

47. Ware JE Jr, Sherbourne CD. The MOS 36-item short-form health survey (SF-36). I. Conceptual framework and item selection. Med Care. 1992;30: 473-83.

48. Lukkarinen H, Hentinen M. Assessment of quality of life with the Nottingham Health Profile among patients with coronary heart disease. J Adv Nurs. 1997; 26:73-84.

49. Prieto L, Alonso J, Ferrer M, Anto JM. Are results of the SF-36 health survey and the Nottingham Health Profile similar? A comparison in COPD patients. Quality of Life in COPD Study Group. J Clin Epidemiol. 1997;50:463-73.

50. EuroQol-a new facility for the measurement of health-related quality of life. The EuroQol Group. Health Policy. 1990;16:199-208.

51. Xie J, Wu EQ, Zheng ZJ, Sullivan PW, Zhan L, Labarthe DR. Patient-reported health status in coronary heart disease in the United States: age, sex, racial, and ethnic differences. Circulation. 2008;118:491-7.

52. Ware J. How to Score Version 2 of the SF-12 Health Survey. Lincoln, RI: Quality Metric; 2005.

53. Vicchio M, De Santo LS, Della Corte A, De Feo M, Provenzano R, Miraglia M, et al Aortic valve replacement with 19-mm bileaflet prostheses in the elderly: left ventricular mass regression and quality of life. J Heart Valve Dis. 2008;17:216-21.

54. Reynolds MR, Magnuson EA, Wang K, Thourani VH, Williams M, Zajarias A et al. Health-related quality of life after transcatheter or surgical aortic valve replacement in high-risk patients with severe aortic stenosis: results from the PARTNER (Placement of AoRTic TraNscathetER Valve) Trial (Cohort A). J Am Coll Cardiol. 2012;60:548-58.

55. Siemiatycki J. A comparison of mail, telephone, and home interview strategies for household health surveys. Am J Public Health. 1979;69:238-45.

56. Brown JM, O'Brien SM, Wu C, Sikora JA, Griffith BP, Gammie JS. Isolated aortic valve replacement in North America comprising 108,687 patients in 10 years: changes in risks, valve types, and outcomes in the Society of Thoracic Surgeons National Database. J Thorac Cardiovasc Surg. 2009;137:82-90.

57. Di Eusanio M, Fortuna D, De Palma R, Dell'Amore A, Lamarra M Contini GA, et al. Aortic valve replacement: results and predictors of mortality from a contemporary series of 2256 patients. J Thorac Cardiovasc Surg. 2011;141:940-7.

58. Krane M, Deutsch MA, Bleiziffer S, Schneider L, Ruge H, Mazzitelli D, et al Quality of life among patients undergoing transcatheter aortic valve implantation. Am Heart J. 2010;160:451-7.

59. Krane M, Deutsch MA, Piazza N, Muhtarova T, Elhmidi Y, Mazzitelli D, et al One-year results of health-related quality of life among patients undergoing transcatheter aortic valve implantation. Am J Cardiol. 2012;109:1774-81.

60. Ussia GP, Mule M, Barbanti M, Cammalleri V, Scarabelli M, Imme S, et al. Quality of life assessment after percutaneous aortic valve implantation. Eur Heart J. 2009;30:1790-6.

61. Sullivan M, Karlsson J, Ware JE Jr. The Swedish SF-36 Health Survey-I. Evaluation of data quality, scaling assumptions, reliability and construct validity across general populations in Sweden. Soc Sci Med. 1995;41:1349-58. 